\title{
Factors Welfare Recipients View Significant to Become Self-Sufficient
}

\author{
Lucson Francois ${ }^{1}$ \\ ${ }^{1}$ Argosy University, USA \\ Correspondence: Lucson Francois, Argosy University, USA. E-mail: 1francois322@yahoo.com
}

Received: August 29, 2017

Accepted: September 26, $2017 \quad$ Online Published: October 18, 2017

doi:10.5539/ijbm.v12n11p1

URL: https://doi.org/10.5539/ijbm.v12n11p1

\begin{abstract}
The purpose of this study was to explore the perceptions of welfare recipients regarding factors significant to becoming self-sufficient in Southeast Florida. The study took a qualitative approach, administering in-depth interviews to 20 current welfare clients. To ensure valid and reliable results, a computer software program known as QSR NVivo 10 was utilized for the accurate coding of responses. Findings in the study suggest that benefits, such as child care, transportation, Medicaid, subsidized employment, housing assistance, and vocational training provided by the government are significant in helping welfare recipients successfully transition from relying on the governmental assistance to obtaining reliable employment with the ultimate goal of becoming self-sufficient; however, their perception differs from policy makers in terms of the benefits provided by the government and how those benefits should be provided. Participants reported that the most helpful programs to their becoming successful were subsidized employment and vocational training. They believed the programs should be redesigned to focus on clients' success. They believed community service did not help them achieve their long- term goal of becoming independent. Implications for social work research and practice are suggested.
\end{abstract}

Keywords: welfare recipients, self-sufficient

\section{Introduction}

In the past 15 to 20 years, various adjustments have been made to welfare programs and social policies through both state and federal government leadership. One of the most difficult challenges at both the federal and state level has been shifting welfare beneficiaries off of welfare and into work. Indeed, many believed that former President Bill Clinton made the biggest adjustment when in 1996 he signed into law welfare policies that offered new choices for families who are in need of assistance from the government (Zuckerman \& Kalil, 2000). Under the 1996 legislation of Temporary Assistance for Needy Families (TANF), the federal government and the state required welfare recipients to participate in work-related activities in order to qualify for TANF benefits (Pavetti, 2000). Prior to this, under the previous Aid to Families with Dependent Children (AFDC), anyone who met the standards of federal and state governments could receive cash assistance with few restrictions (Pavetti, 2000). However, the Personal Responsibility and Work Opportunity and Reconciliation Act (PRWORA) that Clinton also signed, eliminated guaranteed federal cash assistance to unemployed single parents with dependent children.

The PRWORA of 1996 replaced the AFDC program with TANF. The main goal of this move was to modify the perception that the welfare benefits were an entitlement to qualified clients (Pavetti, 2000). When the federal government made that adjustment, Tweetie (2003) found that welfare recipients declined by $35 \%$ nationwide. However, the level of employability of welfare recipients who left the welfare program remained steady (Wexler \& Copeland, 2003). In other words, welfare recipients who left the program due to federal and state requirements remained stable in terms of employment (Wexler \& Copeland, 2003). This indicates that although they left welfare, there was no increase in employment.

Over the years, the federal government pressured the state of Florida to be more innovative in terms of finding ways to effectively transition welfare recipients from relying on the government entitlements to becoming self-sufficient (Rogers-Dilon, 1999). When a client applies and meets the requirements for assistance, that client becomes a mandatory client and then an assessment is conducted to assist that client in becoming self-sufficient within a specific period of time. The state of Florida allows a client to receive 48 months of cash assistance in his or her lifetime. The state provides different forms of assistance to mandatory clients, including childcare, 
transportation, and Medicaid, in addition to the TANF and the Supplemental Nutrition Assistance Program (SNAP).

The state of Florida mandates that a client comply with its requirements for assistance eligibility or the case will be sanctioned. When a case is sanctioned, it affects all forms of assistance, including the TANF and SNAP. During the assessment, the needs of the client are identified, his or her goals are identified, and together the client and the caseworker identify different ways to reach those goals (Florida Department of Economic Opportunity [DEO], 2014). If a client has limited skills, the procedure begins with registering the client in a vocational school or assigning him or her to an organization within an area in which he or she will complete 30 hours or more (up to 40 hours) of community service on a weekly basis. It is important to note that each client is reevaluated every 3 months by his or her assigned case worker until he or she becomes employed and no longer relies on the government for support (Farrell, Rich, Turner, Seith, \& Bloom, 2008). When a client is employed, he or she becomes a transitional client within 30 to 60 days of employment. A transitional client continues to receive limited assistance from the government. Such assistance includes child care, partial Medicaid, a housing voucher, aid with transportation, and bonuses for completion of continuous employment for a period of 90 days, 180 days, and 1 year (Welfare Rules Database, 2015).

Welfare beneficiaries in Florida have limited time to become self-sufficient once they start receiving welfare benefits from the government (Welfare Rules Database, 2015). In the early 90s, the time limit was about 72 months, whereas by the mid-90s, time to become self-sufficient was reduced to 60 months. By late 90 s, the time limit was shortened to 48 months (Bloom et al., 2000). Although various adjustments have been made within the welfare transition program in Florida, recipients continue to struggle to become self-sufficient. The issue with the time limit is that the state becomes more focused on getting the recipients a job than helping them to obtain necessary skills to become successful and sustain employment in the long run. As a result, those recipients go back and forth in the program, or they have to rely on supplementary programs such as housing voucher, child care, and the SNAP program to survive (Bloom et al., 2000).

Findings of the research will be beneficial to the federal government, the State of Florida, along with current and future welfare recipients. Also, the state of Florida will become more aware of the key benefits that welfare recipients value the most in becoming self-sufficient. That way, the voice of the recipients will be heard instead of the federal government and the state maintaining a program that has not been effective for years. Contrary to what certain law makers believed, Tanner and Hughes (2013) discovered that there is no concrete evidence that welfare recipients are lazy or not willing to have full time employment and to keep full time jobs in the long run. Tanner and Hughes (2013) concluded that welfare recipients need help from the government to acquire necessary skills to land jobs that will aid them effectively support their families without relying on the government program.

\subsection{Significance of the Study}

Findings of the research will be beneficial to the federal government, the State of Florida, along with current and future welfare recipients. Also, the state of Florida will become more aware of the key benefits that welfare recipients value the most in becoming self-sufficient. That way, the voice of the recipients will be heard instead of the federal government and the state maintaining a program that has not been effective for years. Contrary to what certain law makers believed, Tanner \& Hughes (2013) discovered that there is no concrete evidence that welfare recipients are lazy or not willing to have full time employment and to keep full time jobs in the long run. Tanner \& Hughes (2013) concluded that welfare recipients need help from the government to acquire necessary skills to land jobs that will aid them effectively support their families without relying on the government program.

\subsection{Research Questions}

This study was guided by four questions:

1. What are the lived experiences of welfare recipients in Dade County Florida who have been in the welfare program for more than 2 years and are not able to obtain reliable employment to successfully transition from welfare to work?

2. What are the most significant assistances the State of Florida needs to include in the welfare transition program that can aid one to become successful without relying on long-term benefits provided by the government?

3. What crucial role do benefits, such as child care, transportation, and Medicaid play in supporting welfare recipients? 
4. How do welfare recipients understand the effectiveness of community service, vocational training, and the subsidized programs?

\subsection{Definitions}

Several vital terms were employed within the research and require additional lucidity regarding their connotations. Those key terms are listed below.

Personal Responsibility and Work Opportunity Reconciliation Act (PRWORA): The PRWORA has been defined as the growing of new time-limited procedures that encourage fast entry into the workforce (Tolman \& Raphael, 2000).

Aid to Families with Dependent Children (AFDC): A program that allowed families with children to collect cash support as long as they met conditions established by both federal and state government (Pavetti, 2000).

One Stop Career Centers: These are centers designed to deliver various forms of assistance to job seekers, employers, low income families, and welfare recipients from both the state and federal government (Mariani, 2014).

Temporary Assistance for Needy Families (TANF): A program that provides limited cash assistance to underprivileged families with dependent children for basics needs such as food, clothing, and housing (Hilderbrandt \& Stevens, 2009).

Transitional benefits: Benefits available to those families who have a job and retain that job. Such benefits include Medicaid, child care, transportation, incentive bonuses and SNAP benefits (Hilderbrandt \& Stevens, 2009).

Supplemental Nutrition Assistance Program (SNAP): A government support program to assist low-income families to pay for food. SNAP was called the food stamp program before President Clinton reformed the welfare program. The amount of SNAP or food stamps a household gets depends on the size of the family, income, and expenses (Welfare Rules Database, 2015).

Mandatory recipients: New clients who enter the program and solely rely on the government for assistance (Welfare Rules Database, 2015).

Transitional recipients: Transitional recipients are mandatory clients who become employed for 30 days or more. After 30 days or more of employment, they become transitional recipients. When the recipients shift from mandatory to transitional status, the government provides only limited assistance to them (Welfare Rules Database, 2015).

\section{Review of the Literature}

Traditionally, policy makers and program developers have attempted to assist welfare recipients in obtaining long-term employment through removing structural barriers. Such structural assistance included child care, transportation, and welfare (Pavetti, 2000). Education, work experience, and incentives are also forms of structural assistance that have different effects on recipients' ability to make a successful transition from welfare to work (Nownes, 2012). Policy makers and program developers have devised various strategies throughout the years; however, welfare recipients have a different perspective on what factors are significant to them as they shift from welfare to work (Herbst, 2013; Yurka, 2012; Zeng, 2011).

The welfare program began in 1930 in the United States. Throughout the years, various adjustments have been made to make the program more effective to both the recipients and the government (Kerlin, 1997). In August 1996, President Clinton signed the PRWORA, which significantly changed the welfare cash assistance program for recipients nationwide (Kerlin, 1997). This chapter will begin by reviewing the PRWORA and the debates that transpired during the consideration of that legislation. It will then describe characteristics of current welfare recipients. Finally, it will review the various factors that welfare recipients view as effective to their ability to be successful in retaining employment. Such factors include child care, transportation, incentives, benefits, subsidized employment, housing assistance, and vocational training.

\subsection{Personal Responsibility and Work Opportunity Reconciliation Act}

The welfare system in the United States was created in 1930 so that single mothers would not have to work once they became recipients (Kerlin, 1997). In early 1960, women with young children began to enter the workforce, and federal and state lawmaker concluded that all welfare recipients should enter the labor market (Kerlin, 1997, in order to become self-sufficient, particularly in the long run. Federal and state policy makers devised different strategies to increase the efforts of welfare recipients to find jobs (Handler, 1995). Two major strategies were 
developed by policy makers: regulatory requirements and incentives (Handler, 1995). The regulatory strategy urged welfare recipients to find a job or engage in work related activities within their respective communities in order to be in compliance with the welfare program (Handler, 1995). The incentive approach challenged welfare beneficiaries to find and retain a job and keep part of their cash assistance for a specific period of time (Handler, 1995). Hence, to some extent, that approach provided financial recompense to welfare recipients who were able to add the money they received from their paychecks to the cash they received from their welfare benefits; this combination was thought to create an incentive to work, rather than exclusively depend on the government for assistance (Wexler \& Copeland, 2003).

Beginning with the Omnibus Budget Act (OBRA) of 1981 under President Reagan, the federal government, followed by the states, increased their use of regulatory strategies (Handler, 1995). Under OBRA, it became difficult for underprivileged families to qualify for Aid to Families with Dependent Children benefits (AFDC; Abramovitz, 1996). In order to qualify for benefits under OBRA, the income of underprivileged families would have to be at $150 \%$ under their state's respective poverty guidelines (Abramovitz, 1996). The requirements even partially applied to pregnant women, whom normally would be exempted under previous legislations. According to Abramovitz (1996), women would not be exempted from the requirements of OBRA until the last 3-month of their pregnancies. Crafton (2014) concluded that President Reagan came up with the OBRA to regulate the welfare program, which he believed was broken under the previous two administrations. Before OBRA, it was fairly easy for a welfare recipient to create different names and receive benefits from the government under each name (Crafton, 2014).

President Reagan and many others from the Senate and Congress shared similar views on how the AFDC program had failed to effectively help families become more self-sufficient (Crafton, 2014). In 1988, the federal government came up the Family Support Act (FSA), which represented a transformation of the system; it was a tactic aimed to deliver federal assistance to families that are in need. Some of the most important applications of the FSA were paternity test, child support collection and obligatory work contribution or community service (Muennig, Rosen, \& Wilde, 2013). Shortly after the enactment of the FSA, George H. Bush took office as president of the United States, and although he did not initiate any significant modification regarding the welfare program, he did encourage states to apply for waivers that would allow them to experiment with different programs and forms of assistance to families with dependent children (Wexler \& Copeland, 2003). Since President George H. W. Bush endorsed the initiative that states could apply different waivers, many states became either more liberal or traditional in respect to their policy and treatment of welfare recipients (Peterson, 1995). Handler and Hasenfeld (1997) agreed that states that were conservative became more traditional, while states that were more liberal became more ample with respect to benefits available to welfare recipients.

In the 1992 presidential campaign in the United States, the issues surrounding welfare program became one of the most important topics of debate between President Bush and presidential candidate Bill Clinton (Handler \& Hasendfeld, 1997). Candidate Clinton promised to end or fix the broken welfare system. Over the following 4 years, welfare reform continued to be debated in Washington between Democrat and Republican law makers (Herbst, 2013). In addition, both Democrat and Republican governors from different states throughout the United States submitted various proposals on how to modify the welfare program (Herbst, 2013). Although there were clear differences between the proposals submitted by Republicans and Democrats officials, the goal of governmental officials from both side of the aisle was to decrease the welfare recipients reliance on government and move those recipients and potential recipients of welfare benefits into the labor force (Dave, Corman, \& Reichman, 2012).

Republicans in Congress were the major power that influenced the welfare reform debate at that time (Handler \& Hasendfeld, 1997). After the Republicans gained control of the house in 1992, they assured the country they would find a way to fix the welfare program (Corcoran, 2000). They started the process by combining different proposals they believed would be appealing to the Senate; and they submitted the proposals for a vote in the house floor (Corcoran, 2000). All the proposals that Republicans in the house came up with had one common denominator: diminished federal involvement in the welfare program and states empowered to decide what would be the most effective for them. In other words, Republican lawmakers decided to increase state control over the welfare program (Cozic, 1997). In addition, the proposals of the Republicans focused on the work requirement rather than social services or education to help welfare recipients become self-sufficient (Cozic (1997).

There were many debates between Republicans and Democrats on how to reshape the welfare program. Congress came up with a proposal that was vetoed by President Clinton due to the restrictions associated with the proposal (Axinn \& Levin, 1997). Although there were restrictions President Clinton and Democratic 
legislators supported from the proposal of the Republicans, the main restrictions included a ban on the use of federal funds for unmarried mothers who were under 18 years of age, strict paternity penalties, and family cap limit (Albramovitz, 1996; Axinn \& Levin, 1997). Between 1992 and 1996, there a series of debates occurred between Republicans and Democrats in Congress to find common ground to repair the welfare program, which both sides of the congress believed was fragmented (Gilens, 1999). Despite the continuity of the Republican majority in Congress, Democratic legislators were able to find common ground with Republicans to present a proposal that was deemed good enough, and it was signed into law by President Clinton.

PRWORA was at last enacted in 1996, and it was a continuation of the 1980s trend of valuing work as a stratagem to assist welfare recipients in gaining independence (Handler \& Hasendfeld, 1997). It was believed that training and education did not push welfare recipients rapidly enough to become self-sufficient (Handler \& Hasendfeld, 1997). Block grants and support for state waivers were also continuations of previous welfare reform efforts (Handler \& Hasendfeld. 1997). The PRWORA substantially change the system of the welfare structure nationally. Such changes included child support, food stamps, Supplemental Security Income (SSI), child protection, child care, and nutritional programs for children (Corcoran, 2000).

There were four key differences between ADFC and TANF: the structure of the funding, individual entitlements, time limits, and work requirements (Corcoran, 2000). However, it is important to note that much of the debate that led to the changes that were enacted by TANF were based on an urban-type of sympathy (Atchinson, 2001). In other words, the final adjustment was not an accurate national representation. Over the years since the adjustments were made by policy makers from the federal government, state lawmakers concluded that modifications had to be made in order to fairly assist families who need aid from the government in their respective states (Schott, 2012).

The goal of the federal government was to reduce the long-term dependence on welfare assistance by endorsing job preparation and work (Schott, 2012). In other words the government wanted to clarify to welfare beneficiaries that public assistance no longer offered lifetime benefits. Instead, the government would provide a short term opportunity to become self-sufficient in the long run (Bitler, Hoynes, Jencks, \& Meyers, 2010). To qualify and receive welfare benefits in Florida, welfare recipients must meet the following criteria:

- Client must reside in the state of Florida at the time of completing the application;

- Client must be a U.S. citizen or a qualified alien lawfully admitted for permanent residence;

- Family must be financially deprived to be eligible;

- All applicants or recipients must provide a Social Security number for each member of the household;

- Children must be under the age of 18 to be eligible or in school and able to complete high school or obtain a GED by the 19th birthday;

- Individuals must be a qualified relative by blood, marriage or adoption;

- Must verify that the child resides in the same home with the qualified relative;

- Client must assign any child support and medical support rights to the state, and he or she must cooperate with the child support agency in establishing paternity or maternity and obtaining child support and medical support from the inattentive parent(s), unless good cause has been established (Florida Department of Children and Families, 2015).

\subsection{Reauthorization of Welfare Alteration}

President George W. Bush unveiled his welfare alteration in 2002, calling for stricter restrictions on work requirements for welfare recipients. The president specified that tougher work requirements needed to be applicable to all welfare recipients, particularly among unwed parents (Serafini, 2004). In addition, President Bush wanted a freeze on current spending associated with welfare programs (Serafini, 2004). After a few long debates, the House of Representative voted and passed the Family Promotion Act (FPA) by 229 to 197 . The act required welfare beneficiaries to complete from 32 to 40 hours of work activity on a weekly basis, and it specified that states must reach a $70 \%$ employment rate among welfare recipients by 2007 , which was an increase of about $20 \%$ from under $50 \%$ (Serafini, 2004). The FPA sustained current funding levels with respect to block grants provided by the federal government to states to source necessary assistance to welfare recipients (Weil \& Finegold, 2002). In an effort to fortify the 32 to 40 hours of work activity initiative on a weekly basis under the FPA, funding for childcare was significantly augmented (Weil \& Finegold, 2002). The increase in funding for childcare program was supported by both federal and states in an attempt to facilitate welfare 
beneficiaries complete their weekly work requirements without the lack of childcare excuses (Weil \& Finegold, 2002).

Once the final version of FPA was completed, the legislature modified the name to Personal Responsibility, Work, and Family Promotion (PRWFP) Act, which was fully supported by Republicans (Serafino, 2004). In contrast to the Republicans, Democrats were not satisfied with the act because there were too many restrictions involved. As a result of the disagreement between Republicans and Democrats, both sides had to compromise; they came up with a new version of the act that they could both support moving forward (Serafini, 2004). The bill was revised and resubmitted under the name of Work, Opportunity, and Responsibility for Kids (WORK) Act (Serafini, 2004). Unlike the previous version of the bill that required welfare beneficiaries to complete 32 to 40 hours per week of work related activity, the new compromise version of the bill required welfare recipients to complete 30 hours per week of work related activity. The requirement that states needed to achieve an employment rate among welfare recipients of $70 \%$ by 2007 remained identical to the previous version of the Act (Weil \& Finegold, 2002).

President Obama wanted to make the welfare program more effective when he took the oval office by giving states more responsibilities and empowering them to make the program more beneficial to welfare beneficiaries (Dave et al., 2012). President Obama encouraged states to consider new, more effective ways to meet the goals of the TANF, particularly helping welfare recipients successfully prepare for, find, and retain employment in order to become self-sufficient (Johnson \& Stephens, 2012). President Obama wanted welfare recipient to become self-sufficient instead of fully or partially relying on the government, which is in contrast to the perception that he wanted to completely change the welfare reform that was created under President Clinton (Barth, Gilmore, Flynn, \& Brekke, 2014). Although there was no major adjustment to improve the welfare program, Barth et al., (2014) suggested that the intention of President Obama was to empower states in term of creating effective programs that could ensure that welfare beneficiaries received the skills and trainings necessary to becoming successful before reaching the federal and state time limit. Gilbert (2009) argued that while the federal government continued to empower states to come up with effective program to help welfare recipients become successful in the long term, it was imperative that states be held accountable when those welfare beneficiaries are not able to become self-sufficient within a specific period of time.

\subsection{Characteristics of Current Welfare Recipients}

Since TANF was implemented in 1996, the number of people participating in the country's financial assistance program for families decreased by 50\%, from 3 million in 1996 to 1.5 million in 2000 ("Characteristics of TANF Recipients," 2012). In 1996, about 9\% of welfare recipients nationally were recipients of AFDC, which was replaced by TANF that year. Four years later, the percentage of all welfare beneficiaries in the United States who received TANF fell to about $4 \%$, and a significant percentage of the recipients were single mothers (Stevenson, 2005). Among TANF mothers who worked in 1998, two-in-three did so voluntarily, while a third said they were required by the welfare office to work (Stevenson, 2005). In addition, about 278,000 single mothers receiving TANF were in training in 1998 , and nearly $75 \%$ of them were learning skills for computer, machinery, or clerical jobs. About $62 \%$ of these mothers also received training in how to find a job ("Characteristics of TANF Recipients," 2012).

\subsection{Racial Disparities}

Stevenson (2005) conducted a study entitled, "Barriers Affecting Women's Ability to Make the Transition From Welfare to Work in a Rural Community," and found that African American single mothers represented a greater quantity of recipients of TANF benefits than people of other races and ethnic groups in many states. The author found that African American single mothers constituted about 38\% of all recipients of TANF benefits. Whites were about $31 \%$ of TANF recipients, Hispanics constituted about $25 \%$ of TANF recipients, and people of other races made up for about $9 \%$ of TANF recipients nationwide.

Stevenson (2005) found that the percentage of TANF families that left the welfare program and that reported their race as White dropped from $42 \%$ in 1997 to 33\% in 1999. The share of TANF-leaving families that reported their race as Black or African American rose from $34 \%$ to $46 \%$ during that same period. The share of families leaving TANF that reported Hispanic ethnicity rose slightly from $18 \%$ to about $21 \%$, as did the share of TANF-leaving families of other races from $3 \%$ to about $4 \%$. African Americans, in contrast to other populations, reported having support networks that assisted them with transportation and childcare (Stevenson, 2005). The same way race and ethnicity influences the likelihood of welfare recipients leaving welfare, so does geographic location. People who live in rural areas apply and receive welfare benefits at a greater proportion than people who live in urban areas. Also, rural poverty rates continue to exceed those of urban areas ("Characteristics and 
Financial Circumstances of TANF Recipients," 2012).

\subsection{Leaving and Returning to the Program}

Recipients living in urban or rural areas are all leaving and returning to the welfare program (Loprest, 2012). In other words, leaving the program and returning to the program are what urban and rural welfare recipients have in common. Loprest (2012) analyzed data from Urban Institutes National Survey of American Families Study to examine the rate that clients leave and return to welfare, which clients return, and the role that transitional supports play in limiting welfare returns. This research focused on families who left welfare for at least 1 month between 1997 and 1999. The most consistent cause for leaving was finding employment or increased earnings (51\%). Another $22 \%$ left because they no longer wanted or needed TANF benefits or because they had increased their income. Thirteen percent left because they were not able to comply with the requirements of the welfare program. Finally, 14\% left for various other reasons, such as moving, children reaching the age limit, or families reaching their time limit (Loprest, 2012). New (2008) argued that many welfare recipients leave the program as a result of the state sanctioning their case. Reasons for sanctioning cases include noncompliance with the program requirements, child support requirements, and unreported earned income (New, 2008).

Loprest (2012) found within the same study that about $22 \%$ of families leaving welfare at some point between 1997 and 1999 had returned by the time he conducted his study in 1999. Recipients who left the program with limited work experience, little education, and health problems were likely to need additional welfare assistance. Those whose most recent employment experience was more than 3 years prior to entering the welfare program $(39 \%)$ and those in poor mental or poor physical health $(28 \%)$ were most likely to return to the welfare program (Loprest, 2012). While Loprest gave characteristics of recipients who were likely to return to the program, Sheely (2012) believed the primary reason why welfare beneficiaries leave the program and go back is due to the states being ineffective in getting the clients "work ready" before they enter the workforce.

The Survey of Income and Program Participation who examined state and county welfare beneficiaries who leave the welfare program reported a comparably significant off-and-on movement (Bavier, 2001). The percentage of people who leave the welfare program and come back to the program within a year or less after leaving ranged from $11 \%$ to $25 \%$ in Florida, in which available jobs, education, and transportation were some of the reasons for the differences (Bavier, 2001). Sixty-seven percent of welfare beneficiaries who exited the welfare program become employed in their first year after exiting the welfare program and less than half of that $67 \%$ remained employed for a year or more. About $40 \%$ of those who became employed worked 35 hours a week or more for the entire year of employment, and an additional $7 \%$ worked 35 hours a week or more in at least 6 months of their first year of employment (Bavier, 2001).

\subsection{Factors Welfare Beneficiaries View as Important}

Policy makers and program developers do not widely diverge when reporting the factors welfare recipients view as important as they transition from welfare to work (Crafton, 2014). Pavetti (2000) concluded that the difference among them has to do with the application. Policy makers and program developers believe important factors such as child care, transportation, and incentives are extremely significant to welfare beneficiaries as they transition from welfare to work. Although it may be true that welfare recipients view those factors as substantial, effective application of those programs vary (Herbst, 2013). Research indicates that factors, such as lack of schooling, job training, and work experience are equally important to welfare recipients to successfully transition from welfare to work (Law, 2008). In other words, those factors are noteworthy to welfare recipients throughout the transitional process. Law (2008) concluded that each welfare beneficiary is affected by at least one of those factors as they attempt to become self-sufficient instead of relying on assistance from the government to survive.

\subsection{Summary}

The issue of welfare remains an object of debate at both the federal and state level, and legislation designed to address the needs of unprivileged people creates controversy as well (Nownes, 2012). In addition, legislative reform efforts have employed regulatory and incentive strategies to address the issues associated with the welfare transition program, with regulatory strategies gaining prominence since the 1980s. The PROWRA of 1996 and the introduction of TANF changed the welfare system nationwide (Wexler \& Copeland, 2003).

The literature suggests that there are different factors that can affect welfare beneficiaries as they shift from welfare to work. The literature also reviews the PRWORA and the debates that transpired during the consideration of that legislation. In addition, it describes characteristics of current welfare recipients. Furthermore, various barriers that can affect welfare recipients as they make the transition from relying on the government for aid to becoming self-sufficient were covered. Such factors include child care, transportation, 
incentives, benefits, subsidized employment, housing assistance, and vocational training. Sheely (2012) stated that many welfare beneficiaries have limited skills and experiences. As a result, job insecurity and the inability to be promoted to higher earning positions have been connected to persistent feelings of panic, frustration, and stress, which could have negative effects on their job success and family well-being.

The study was conducted from a phenomenological perspective (Creswell, 2007; Fink, 2010; Moustakas, 1994). The goal of phenomenology is to describe the essence of a lived experience that is shared by multiple individuals. Psychological phenomenology (Moustakas, 1994) focuses on describing the experiences of participants, and minimizes the role of the researcher's interpretations of those experiences. This was a phenomenological study from the standpoint that the researcher was interested in exploring the lived experience of welfare recipients in Southeast Florida. Johnson and Christenses (2008) specified that a qualitative study is conducted to understand and interpret social interaction.

Often data collection in phenomenological studies consists of in-depth interviews and multiple interviews with participants. It was determined by academic advisors and the researcher that in-depth interview technique was a good procedure to explore the factors welfare recipients in Dade County Florida view as significant to successfully make the transition from welfare to work. Moustakas (1994) stated that data are collected from the individuals who have experienced the phenomenon. The participants were selected in the specified area from One Stop Career Centers. Data were collected from in-depth face-to-face interviews. The researcher utilized four central research questions and follow up questions, in order to fulfill the objective of the study. Notes were taken throughout the different meetings. Once all the data collected for the study, the researcher analyzed the data to enhance understanding of the lived experiences of welfare recipients in Southeast Florida who have been in the welfare program for more than 2 years, and who were not able to obtain reliable employment to successfully make the transition from welfare to work. Fink (2010) concluded that participants feel more comfortable answering questions about specific issues when the interview is being conducted at an innocuous location where the participants feel protected.

All of the interview sessions were being conducted at Homestead Church of the Nazarene in Southwest of Dade County Florida. Homestead Church of the Nazarene was selected since it is located in the central of Southwest of Dade County, Florida surrounding by different One Stop Centers where welfare beneficiaries receive services. In addition, Homestead Church of the Nazarene is located within a walking distance from public transportation. The state of Florida provides transportation assistance to mandatory and transitional welfare clients every month. Such assistance includes free passes to public transportation for welfare clients who do not have vehicles; clients who do have vehicles receive assistance to purchase gasoline in the form of charge cards that can only utilize to purchase gasoline (Welfare Transition, 2014).

\subsection{Sample}

Twenty different welfare recipients were selected in the specified area from different One Stop Career Centers. Creswell (2006) concluded that for a phenomenological study, the process of collecting information involves primarily in- depth interviews with 15 to 25 participants. The criteria for participating in the study included being an adult over the age of 18 . Welfare beneficiaries also needed to have lived in Dade County, and have been receiving assistance from the government for at least 2 consecutive years. Each participant also had to have a child under the age of 13 , because child care is part of the benefits of the program and those in need of childcare were thought to represent the population under study. Welfare beneficiaries in Dade County Florida are predominantly single parents with a minimum of one child under 13 years of age (South Florida Workforce, 2014). Although unemployed parents with children under the age of 18 years can apply and qualify for welfare benefits, according to South Florida Workforce (2014), a significant percentage of welfare recipients in Florida are single parents with at least one child under the age of 13 years.

Dade County Florida was chosen because it is one of the most populated counties in Florida that has more different One Stop Centers than any other county within the state. Dade County, Florida has 12 One Stop Career Centers and the county is located in the southeastern part of the state of Florida (South Florida Workforce, 2014). Dade County, Florida encompasses more than 2,000 square miles (South Florida Workforce, 2014). As of August 2014, the population of the county is 2,617,176. Between 2010 and 2014, the population of Dade County increased by $4.8 \%$ (United States Census Bureau, 2014). Sixty five percent of the population in Dade County Florida are classified as Hispanic or Latino, $19 \%$ of the population in Dade County Florida is classified as African American or Black, $15 \%$ of the population are White, $1.7 \%$ of the population are Asian, $1.2 \%$ of the population identify as biracial and multiracial, and $0.3 \%$ of the population are classified as American Indian 
(United States Census Bureau, 2014). Only English speaking participants were selected to participate in the study.

Dade County, Florida has several major types of employers, which include transportation, utilities, business and professional, leisure and hospitality, construction, education and health services (Bureau of Labor Statistics, 2014). The median household income in Florida is $\$ 41,533$, and people living under the poverty line in the county are about 21\% as of 2013 (Department of Regulatory and Economic Resources, 2013). In other words, $21 \%$ of the Dade county residents live within or below the poverty line as of 2013.

\section{Methodology}

Permission to interview participants in the Church of the Nazarene was requested and granted. An initial flyer was created and was posted at the community bulletin board at different One Stop Centers in Dade County Florida. Welfare participants who were interested in participating in the study were asked to call or email the researcher to confirm that they are willing to participate. Once initial contact made with potential clients, the nature of the study was explained to them and the pertinent aspects of the consent form. The researcher explained to each potential participant that being part of the inquiry was voluntary, and there would not be any monetary compensation or any other reward for participating. Also, the researcher explained to each potential participant that his or her privacy would be kept confidential, and an informed consent would be provided.

It was also explained to participants that they would be able to withdraw and discontinue participation at any time without penalty. Furthermore, the researcher explained to potential participants that once they agreed to participate, and if they met the requirements to participate in the study, their information would be collected and they would be contacted once all the participants are selected. Those still interested in participating were then asked several questions regarding the demographics of that participant, including age, status as a welfare recipient, how long he or she has been in the program, whether he or she had children under 13, and whether he or she were currently living in Dade County Florida. Those that met the criteria for the study were told that they would be contacted at a later date to inform them whether they were selected for the study. The researcher attempted to select participants in terms of their proportional representation in Dade County Florida. Creswell (2008) concluded that to avoid bias in the selection of participants for a study, the researcher needs to randomly select the participants. The researcher assigned a number to each potential participant and randomly selected a few participants from each demographic group.

The participants that were selected were provided a date, time, and location to meet in order to conduct the interview. The 20 participants were interviewed individually. The strategy was to administer in-depth interviews in an effort to understand and interpret experiences of those welfare clients. The target population included Hispanic or Latino, African American or Black, White, and other. Each question was formulated concisely to assure participants comprehend what was being asked.

Each interview session lasted approximately 45 minutes. A one-on- one interview session was conducted to avoid infringement on privacy at Homestead Church of the Nazarene. Different sessions were scheduled on different dates and times including weekends to give participants the flexibilities to show up without interfering with their personal schedules. The setting of the conference room where the interview was being conducted was as follows: There was one table, and one chair on each side of the table. The researcher was sitting in a position to be able to observe participant's facial expressions and gestures throughout the interview. A computer was being utilized to take notes along with a notebook and a pen.

No recording device was utilized since participants declined to have their responses recorded. Researchers are responsible for ensuring that participants are not harmed, privacy is maintained, and the participants have provided informed consent (Lincoln \& Guba, 1985). Consent for participation is very important as well as when it comes to ethical issues. Each participant signed the informed consent prior conducting the interview session; and a copy of the consent was made available to each participant. Codes were utilized while taking notes as a way to label, compile, and organize data.

All major qualitative methods employ coding techniques to help organize and analyze the overwhelming amount of data that are frequently collected during qualitative research (Gibbs \& Taylor, 2010). Regardless of the qualitative method, coding is the process of focusing a mass amount of free-form data with the goal of empirically illuminating answers to research questions. Coding moves in a stepwise fashion progressively from unsorted data to the development of more refined categories, themes, and concepts (Gibbs \& Taylor, 2010). In regards to the procedures, the following steps were followed: Permission to conduct research, request and appreciation for participation, consent, demographic questionnaire, and interview protocol. 


\subsection{Instrumentation}

The instrument used in this study was an interview protocol. An in depth interview can be a concrete tool to apply in a qualitative research, since open-ended questions allow the interviewer to deeply explore the respondent's feelings and perspectives on a particular subject (Boyce \& Neale, 2006). Boyce and Neale (2006) stated added that such strategy can add rich background information that can shape further questions relevant to the topic. One of the key characteristics of in-depth interviews is use of the open-ended question, which give participants the freedom to answer the questions using their own words.

\subsection{Validity and Reliability of Methods}

When initiating a qualitative research project, it is essential that the researcher understand the variety of methods available and the relationships among research questions, methods, and desired results (Creswell, 2008). The credibility of an inquiry must be evaluated in the context of accepted standards that are used for such purposes. Credibility can be enhanced by the care the research takes in conducting skilled in-depth interviews, extensive observations, and in collecting documentary data (Patton, 2002). Credibility can be enhanced by prolonged engagement in the field, and use of multiple visits and multiple sites.

\section{Data Analysis}

The researcher analyzed data by typing notes from the responses from interviews, making observational notes, and entering responses to questions into Microsoft Word. In addition to the utilization of Microsoft Office software, such as Word, Excel, and Access, the NVivo10 software was utilized to analyze data collected from the interview. NVivo10 is designed for qualitative researchers who need to deep levels of analysis for small or large volumes of data; and this software has always set the standard in qualitative analysis (Bazeley, 2007). Also, the software works with audio and visual material, and new tools mean deeper and more flexible analysis is possible (QSR International, 2010). Bergin (2011) concluded that the NVivo10 is one of the most reliable software to utilize in a qualitative inquiry. Using software in the data analysis process has been thought by researchers to add rigor to qualitative research. Debate on the usefulness of the concepts of validity and reliability in qualitative research has been undertaken for many years (Welsh, 2002).

One way in which such accuracy can be achieved is by using the search facility in NVivo10, which is viewed by the product designers as one of its main assets facilitating analysis of the data (Bergin, 2011). Utilizing such software helped the researcher analyze data collected from the interview sessions. An important key element in qualitative data analysis is the systematic coding of text; codes are the building blocks for theory or model building and the underpinning on which the arguments of a researcher repose (MacQueen, 2000). Coding in a research helps one combines data for themes, ideas, and categories and then marking similar passages of text with a code label so that they can readily be recovered in the future or a later period for further comparison and analysis.

Using NVivo makes the process easier to search for information, to make comparisons, and to identify patterns that require additional analysis (Gibbs \& Taylor, 2010). Codes allow the researcher to summarize and synthesize what is occurring in his or her data. In linking data collection and interpreting the data, coding becomes the basis for developing themes. Coding is part of the analysis process in a qualitative research (Creswell, 2008). One may utilize different techniques to identify themes and codes, including word repetitions, key words in context, comparison and contrasting, searching for missing information, metaphors and analogies, transitions, connectors, and unmarked text (Ryan \& Bernard, 2003).

Regardless of the type of interview being coded, certain basic steps are essential to code information reliably. In each of those steps, difficulties can arise depending on the type of data and the purpose for which it is to be utilized (Gorden, 1992). The following are the coding steps that were utilized to code the collected data: First, the researcher read each narrative thoroughly, both as the narrative was entered into the analysis software and immediately before beginning the coding process. The next step was horizontalization (Moustakas, 1994), which involved looking for passages, sentences, or quotes that represent significant elements welfare recipients view that can help them make the transition from welfare to work in Southeast Florida. For example, participants discussed how difficult it is to afford child care costs, monthly share costs on their rental and Medicaid while earning a minimum wage. Each of these significant pieces of information was assigned a code that represented its content.

From the significant statements identified in the horizontalization step, the researcher developed clusters of meaning or code families (Moustakas, 1994). Clusters of meaning or codes families bring together significant statements into groups based on similar themes. For example, if several participants mentioned that earning 
minimum wage is the reason they are not able to make the transition from welfare to work, then that could be a cluster of meaning, even if they each had slightly different experiences of that general theme.

Thematic analysis is a flexible analytical methodology that allows for analysis within many theoretical traditions; it is an iterative process rather than a linear process (Creswell, 2007). The researcher underwent multiple iterations of generating codes, reviewing themes, refining codes, and grouping themes. Those multiple repetitions helped to ensure that the codes and themes were representative of the data and were grouped reasonably. Finally, from the textural and structural descriptions, the researcher created a final composite description that contained the essence of the phenomenon (Moustakas, 1994) for each group. Throughout this description, ideas and conclusions were supported by representative quotes from the narratives. Presentation of the essential description contains analysis, comparisons, contrasts, connections with existing literature, and appropriate explanation.

\section{Results}

The researcher presented data analysis and findings from the interviews with the welfare recipients in Dade County, Florida. The researcher employed qualitative thematic analysis to discover themes to help address the research questions of the study. In addition, NVivo10 was also utilized for a more organized and accurate coding of the responses. Overall, the six themes answered the first research question: what are the lived experiences of welfare recipients in Southeast Florida who have been in the welfare program for more than 2 years and are not able to obtain reliable employment to successfully make the transition from welfare to work? It was then established that learning and acquiring skills was the most significant assistance that the State of Florida needs to include in the welfare transition program in order to aid welfare recipients in becoming successful and no longer needing long term benefits provided by the government.

In addition, it was found that child care, transportation, and Medicaid were all helpful in providing financial support. Finally, welfare recipients believed that subsidized employment provides work experience and above minimum wage compensation, that vocational training is crucial to acquire knowledge and skills, and that community service is a waste of time. Additional follow-up interviews were conducted with the participants for further analysis. Responses from participants helped to compare and contrast different factors. Concept mappings were also utilized to show the inter-relationships of codes. In the next chapter, the conclusions, recommendations, and limitations of the study will be presented.

\subsection{Summary}

Amongst the different factors welfare recipients in Southeast Florida view as significant as they make the transition from relying on the government for assistance to obtain employment to become self-sufficient, participants within the study voiced that all the factors including child care, transportation, incentives, Medicaid, subsidized employment, housing assistance, and vocational training are significant in aiding them to make such transition, with the exception of the community service policy. The total sample stated that the community service policy is "a waste of time." In addition, many participants shared the feeling of being "useless and incompetent" when they were being assigned to a community service worksite by their respective case managers. Social work practitioners may further assist this population by assigning participants to vocational training and other activities that will potentially help them acquire skills and work experiences to help obtain reliable employment to make the shift from welfare to work.

Subsidized employment can be of assistance to welfare recipients financially in short run, and in the long run, it can help them gain vital experiences to land a long-term reliable employment in the workforce (Baker \& Bernstein, 2013). Skills and work experience are important to compete in the workplace. In a qualitative study conducted by Taylor and Seale (2013), the authors found that one of the reasons why welfare recipients are not able to compete in the workplace is associated with their limited work experience and skills. With more work experience and skills, welfare clients would be able to acquire long-term employment and effectively compete in the workplace (Taylor \& Seale, 2013). The findings of Taylor and Seale's study suggest that valuable work experiences and vocational training program to acquire knowledge and skills are important to welfare clients to become successful.

Although transportation, childcare, Medicaid, incentives, subsidized employment, vocational training, and housing assistance variables did not differentiate these welfare recipients in terms of their employment status, participants within the study clearly articulated their frustration with the copayments on those variables once they obtain employment and their status changes from being mandatory participants to become transitional participants. Their financial resources are in short supply and represent potential constraints to long-term 
success. Social work practitioners and administrators may further assist this population by working to find ways to decrease the amount welfare beneficiaries contribute on those variables once they obtain employment.

Despite the fact that participants noting the challenges of public transportation, participants managed to find ways to get to and from work regardless of limited public transportation routes, and their willingness to make the transition from welfare to work with inadequate capital was truly astonishing. In addition, participants managed to pay their monthly share cost on their lease and daycare without letting their financial hardship become an obstacle in their motivation to make the transition from welfare to obtain reliable employment.

\subsection{Research Implications}

The results of the study hold important implications for social workers who work with welfare recipients. The literature suggests that there are different factors that can affect welfare beneficiaries as they shift from welfare to work. Such factors include; child care, transportation, Medicaid, incentives, subsidized employment, housing assistance, and vocational training (Crafton, 2014). Findings from this study my provide policy makers, administrators, social workers, and public health workers with a better understanding of the various factors that welfare recipients view as significant and their perception of what needs to be included in the policies to help them make the transition from welfare to work.

\section{Conclusion}

Using in-depth interviews to collect data, this study examined the factors welfare recipients view as significant in becoming self-sufficient in Southeast Florida. The study's findings supported previous research that has suggested that policy makers and program developers come up with different strategies throughout the years; however, welfare recipients have a different perspective on the factors that are significant to them as they make the transition from welfare to work (Herbst, 2013; Yurka, 2012, Zeng, 2011). These study's findings suggest that the policies created by the government to help welfare clients become successful may not be the most efficient and or effective way to help individuals move from public assistance to financial independence. The findings from this study may suggest that a change in policy development is warranted. The authentic responses of welfare recipients in Southeast Florida offer a way to proceed in order to meet the needs of welfare recipients in making a successful transition from welfare to work.

Tanner and Hughes (2013) discovered that there is no concrete evidence that welfare recipients are lazy or not willing to have full time employment or to retain full time employment in the long run. The authors concluded that welfare recipients need help from the government to acquire necessary skills to find employment that will aid them in effectively supporting their families without having to rely on the government for assistance. The findings of this study suggest that it may be necessary to move away from the traditional hierarchical premise in which policy makers assume an all-knowing and authoritarian position when it comes to what assistances to provide to welfare recipients. While the government and welfare recipients in Southeast Florida believe benefits such as child care, transportation, Medicaid, subsidized employment, housing assistance, and vocational training are significant factors that can aid welfare recipients to make the transition from welfare to become self-sufficient; nevertheless, welfare recipients perspective of how to implements those benefits and duration of such benefits are very different from the government in many ways. Yet welfare recipients' willingness to overcome welfare to work barriers with limited resources is extraordinary.

Welfare recipients in Southeast Florida deserve to make the transition to work in a fashion that will allow them to become productive participants in the labor force. Policy makers have an obligation to ensure that this happens by finding a comprehensive way to incorporate welfare recipients' perspectives in the policy. After all, the policies implemented by the government in the past with policy makers assuming an all-knowing and authoritarian position have not been effective in terms of assisting welfare recipients in making the transition from welfare to work. The findings from participants suggest that they need greater support to make this transition, reliable, subsidized employment to gain skills and experience, vocational training, and time to find and retain work. They are motivated to become independent, and they ask that the policy be shaped around the common goal: clients' success in the workplace.

\section{Limitations and Delimitations}

Limitations are potential weaknesses in an analysis, which in most cases are out of control of an examiner (Leedy \& Ormrod, 2010). The first and most obvious limitation is that clients might not give honest answers to the questions. In other words, the clients may provide answers they think would satisfy the researcher. To reduce the prospect of clients providing answers they think the researcher would want to hear from occurring, the researcher explained to participants that there was no wrong or right answer to the questions and all answers will 
be kept confidential. The researcher made it clear to the participants that the researcher is not in a position of authority within the welfare system in Florida or the federal government. Another limitation of the study is the limits of the knowledge of the clients as to what really is causing the problem that prevents welfare beneficiaries from successfully shifting from welfare to work.

Leedy and Ormrod (2010) specified delimitations are characteristics that limit the scope and delineate the boundaries of an inquiry; and are controlled by the researcher.

The purpose of the inquiry was to determine factors that welfare recipients view as important to become self-sufficient in Dade County Florida. A delimitation of the study was that it was conducted in a convenient area in Southeast Florida and the findings may not be the generalizable of other areas in the country. The focus on current welfare recipients in the inquiry was also a limitation. All participants in the study were residents of Dade County Florida.

To address some of the limitations of this research, this study can be replicated with a larger population. There are limited studies that focus on different factors welfare recipients view as significant to make the transition from relying on the government for assistance to becoming self-reliant through work. Therefore, a study design similar to the one implemented in this study could be utilized with larger samples to identify the relative importance of these different types of factors.

\section{References}

Baker, D., \& Bernstein, J. (2013). Getting back to full employment, a better bargain for working people. Washington, DC: Center for Economic and Center Research.

Bavier, R. (2001). Welfare reform data from the survey of income and program participation. Monthly Labor Review, 124(7), 12-25.

Bazeley, P. (2007). Qualitative data analysis with NVivo (2nd ed.). Thousand Oaks, CA: Sage.

Bergin, M. (2011). NVivo 8 and consistency in data analysis: Reflecting on the use of a qualitative data analysis program. Nurse Researcher, 18(3), 6-12.

Bloom, D., Kample, J. J., Morris, P., Scrivener, S., Verma, N., \& Hendra, R. (2000). The family transition program: Final Report on Florida initial time-limited welfare program. Retrieved from MDRC website: http://www.mdrc.org/publication/family-transition-program

Boyce, C., \& Neale, P. (2006). Conducting in-depth interviews: A guide for designing and conducting in-depth interviews for evaluation input. $\quad$ Retrieved from http://www.pathfind.org/site/DocServer/m_e_tool_series_indepth_interviews.pdf? docID=6301

Bureau of Labor Statistics. Employers in Miami Dade County. (2014). Retrieved from http://www.bls.gov/ro4/cesmia.pdf

Crafton, W. (2014). The incremental revolution: Ronald Reagan and welfare reform in the 1970s. Journal of Policy History, 26(1), 27-47. http://dx.doi.org/doi:http://dx.doi.org/10.1017/S0898030613000365

Creswell, J. (2006). Qualitative inquiry and research design: Choosing among five approaches (2nd ed.). Sage. Retrieved from http://digitalbookshelf.argosy.edu/books/9781412989220/3/2

Creswell, J. W. (2009). Research Design. Qualitative, qualitative and mixed methods approaches (3rd ed.). Thousand Oaks, California: Sage.

Department of Regulatory and Economic Resources. (2013). Miami, Florida (FL) income map, earnings map, and wages data. Retrieved from http://www.city- data.com/income/income-Miami-Florida.html

Farrell, M., Rich, S., Turner, L., Seith, D., \& Bloom, D. (2008). Welfare time limits an update on state policies, implementation, and effects families. Retrieved from http://www.acf.hhs.gov/sites/default/files/opre/welfare_time_limits_an_update_o n_state_policies_implementation_and.pdf

Fink, A. (2010). Conducting research literature reviews (3rd ed.). Thousand Oaks, California: Sage.

Florida Department of Economic Opportunity. (2014a). Temporary assistance for needy families (TANF). Retrieved from http:/www.dcf.state.fl.us/programs/access/docs/TANF\%20101\%20final.pdf

Florida Department of Economic Opportunity. (2014b). Welfare transition program. Retrieved from http://www.floridajobs.org/office-directory/division-of-workforce-services/workforce-programs/welfare-tra nsition-program 
Gibbs, G. R., \& Taylor, C. (2010). How and what to code. Retrieved from University of Huddersfield website: http://onlineqda.hud.ac.uk/Intro_QDA/how_what_to_code.php

Gorden, R. (1992). Coding interview responses. Retrieved from Indiana University website: http://www.indiana.edu/ educy520/sec5982/week_5/qual_data_analy_ex2.pdf

Herbst, C. M. (2013). Welfare reform and the subjective well-being of single mothers. Journal of Population Economics, 26(1), 203-238. http://dx.doi.org/http://dx.doi.org/10.1007/s00148-012-0406-z

Hilderbrandt, E., \& Stevens, P. (2009). Impoverished women with children and no welfare benefits: The urgency of researching failures of temporary assistance for needy families program. American Journal of Public Health, 99(5), 793-801. http://dx.doi.org/10.2105/AJPH.2006.106211

Johnson, B., \& Christenses, L. (2008). Educational research: Quantitative, qualitative, and mixed approaches. Thousand Oaks, CA: Sage.

Kerlin, A. (1997). From welfare to work: Does it make sense. Journal of Sociology \& Social Welfare, 1(20), 71-85.

Law, J. Y. (2008). Changing welfare "as we know it" one more time: Assuring basic skills and postsecondary education access for TANF recipients. Santa Clara Law Review, 1(48), 243-278.

Leedy, P. D., \& Ormrod, J. E. (2010). Practical research: Planning and design (9th ed.). New York, NY: Merrill.

Lincoln, Y. S., \& Guba, E. G. (1985). Naturalistic inquiry. Beverly Hills, CA: Sage.

MacQueen, K. M. (2000). Codebook development for team-based qualitative analysis. Cultural Anthropology Methods, 10(2), 31-37. Retrieved from http://www.cdc.gov/hiv/pdf/library_software_answr_codebook.pdf

Mariani, M. (2014). One-stop career centers: All in one place and everyplace. Occupational Outlook Quarterly, 1(202), 606-612. Retrieved from http://www.doleta.gov/usworkforce/onestop/pdf/1stop.pdf

Moustakas, C. (1994). Phenomenological research methods. Thousand Oaks, CA: Sage.

Muennig, P., Rosen, Z., \& Wilde, E. T. (2013). Welfare programs that target workforce participation may negatively affect mortality. Health Affairs, 32(6), 1072-1077.

Nownes, A. J. (2012). The politics of policy change: Welfare, Medicare, and social security reform in the United States. Choice, $50(3), 570$.

Patton, M. Q. (2002). Qualitative research and evaluation methods. Thousand Oaks, CA: Sage.

Pavetti, L. A. (2000). Creating a new welfare reality: Early implementation of the temporary assistance for needy families program. Journal of Social Issues, 56(4), 501-516.

Peterson, P. E. (1995). The price of federalism. Washington, DC: The Brookings Institution.

QSR $\quad$ International. (2010). Retrieved from ftp://140.118.199.9:2100/PUBLIC9/2011_ALL/zResearch_2010/2010Q1b_Groud ed-Theory/4_Tool_Nvivo/Tutorials--Nvivo8-VIdeoDownload.pdf

Rogers-Dilon, R. H. (1999). Federal constraints and state innovation: Lessons from Florida family transition program. Journal of Policy Analysis and Management, 18(2), 327-332. doi: 10.1002/(SICI)1520-6688(199921)18:2<327::AID- PAM7>3.0.CO;2-Z

Ryan, G. W., \& Bernard, R. H. (2003). Techniques to identify themes. Field Methods, 15(1), 85-109. doi:10.1177/1525822X02239569

S. Census Bureau. (2014). State and county quick facts. Retrieved from http://quickfacts.census.gov/qfd/states/12/12086.html

Sheely, A. (2012). Devolution and welfare reform: Re-evaluating success. Social Work, 57(4), 321-331.

South Florida $\quad$ Workforce. $\quad$ (2014). Solutions. $\quad$ Retrieved from http://www.careersourcesfl.com/SFWsolutions/August2012/SFWnewsAUG2012_rev080312L.pdf

Tanner, M., \& Hughes, C. (2013). The work versus welfare trade-off. Retrieved from Cato Institute website: http://object.cato.org/sites/cato.org/files/pubs/pdf/the_work_versus_welfare_trade-off_2013_wp.pdf

Tolman, R. M., \& Raphael, J. (2000). A review of research on welfare and domestic violence. Journal of Social Issues, 56(4), 655-682.

Tweetie, J. (2003). Rapid assistance for TANF families. Proceedings of the National Conference of State 
Legislators, Dallas, TX.

Welfare Rules

Database.

(2015).

Retrieved

from

http://anfdata.urban.org/wrd_test/Distribution/WRDDistribution.CFM?1Var=2929.0

Welsh, E. (2002). Dealing with data: Using NVivo in qualitative data analysis process. Qualitative Social Research, 3(2). Retrieved from http://www.qualitative- research.net/index.php/fqs/article/view/865/1880

Wexler, S., \& Copeland, V. (2003). Combating family poverty: A review of the American welfare system. In H. Wallace, G. Green, \& K. Jaros (Eds.), Health and welfare in the 21st century (2nd ed., pp. 119-137). Boston, MA: Jones and Bartlett.

Zuckerman, D. M., \& Kalil, A. (2000). Introduction: Welfare reform: Preliminary research and unanswered questions. Journal of Social Issues, 56(4), 579-586.

\section{Copyrights}

Copyright for this article is retained by the author(s), with first publication rights granted to the journal.

This is an open-access article distributed under the terms and conditions of the Creative Commons Attribution license (http://creativecommons.org/licenses/by/4.0/). 